\title{
OS IMPACTOS DO PROGRAMA DE FORMAÇÃO DE PROFESSORES NAS PRÁTICAS DE FORMAÇÃO DOCENTE NO DEPARTAMENTO DE GEOGRAFIA DA USP
}

Eduardo Donizeti Girotto ${ }^{1}$

Resumo: No presente artigo, resultado de pesquisa de doutorado realizado junto ao Programa de Pós-graduação em Geografia Humana do Departamento de Geografia da Universidade de São Paulo, analisamos mudanças ocorridas no ensino e na formação docente em geografia a partir do processo de implementação do Programa de Formação de Professores (PFP-USP) lançado por esta Universidade em 2006. Nosso intuito é analisar de que maneira o PFP-USP tem norteado as decisões institucionais e práticas que envolvem a formação do professor de geografia, bem como os desafios que traz para o DG-USP. Para tanto, recorremos a pesquisas documentais na Instituição e em outros bancos de dados que se referem à formação de professores na USP. Além disso, aplicamos questionários $e$ realizamos entrevistas com docentes e discentes do referido departamento e de outros institutos e faculdades da universidade que, direta ou indiretamente, tiveram algum grau de participação no processo de construção de implementação do PFP-USP, para que assim pudéssemos analisar as diferentes perspectivas e práticas que ali existem, bem como os desafios para que o programa se efetive.

Palavras-chave: Formação Docente; Geografia; Currículo.

\section{THE IMPACTS OF THE TEACHER EDUCATION PROGRAM IN THE PRACTICES OF TEACHER EDUCATION IN THE DEPARTMENT OF GEOGRAPHY AT USP}

\begin{abstract}
In this paper, result ofdoctoral research conducted by the Graduate Program in Human Geography, Department of Geography, São Paulo University, we analyze changes in teaching and teacher training in geography from the process of implementing the Teacher Education Program (PFP-USP) launched by this University in 2006. Our aim is to analyze how the PFP-USP has guided the decisions and institutional practices that involve the training of teachers of geography and the challenges it brings to the DG-USP. Therefore, we resorted to documentary research in the institution and in other databases that refer to teacher education at USP. Furthermore, we apply questionnaires and conducted interviews with teachers and students of that department and other institutes and faculties of the university, directly or indirectly, had some degree of involvement in the construction process of implementation of PFP-USP, so that we could analyze the different perspectives and practices that exist there, as well as the challenges for the program to become effective.
\end{abstract}

1. Doutor em Geografia Humana, USP. Professor Adjunto do Colegiado de Geografia da Universidade Estadual do Oeste do Paraná (egirotto@ig.com.br). 
Key words: training teachers; geography; curriculum.

\section{INTRODUÇÃO}

A Universidade de São Paulo (USP) destaca-se como a principal do país e uma das mais do continente americano. Criada em 1934, teve importante participação em diferentes momentos da história do país, seja através da ação direta, como no caso do enfrentamento (e também do apoio) a ditadura militar, seja indiretamente com a formação de intelectuais influentes nos diversos movimentos sociais e políticos ocorridos.

Em relação ao curso de Geografia da USP, o mesmo completou, em 2014, 80 anos de existência, tendo sido criado ao mesmo tempo da fundação desta Universidade. Tal afirmação nos possibilita compreender o lugar deste departamento no processo de institucionalização da ciência geográfica no país, bem como o lugar que atualmente ocupa na hierarquia deste campo disciplinar. Trata-se de um dos principais departamentos de geografia do país, responsável por grande parte das pesquisas produzidas em diferentes áreas deste campo disciplinar é reconhecida por sua participação em momentos historicamente decisivos na consolidação desta ciência no país.

Estas duas informações são fundamentais para entendermos que as discussões acerca da formação de professores no Departamento de Geografia da USP (DG-USP) devem ser interpretadas, também, a partir das relações estabelecidas com os caminhos próprios que esta formação teve na constituição da Universidade. Não se trata de caminho único, mas de diversas experiências que foram ganhando contornos diferentes com o tempo a partir das propostas dos diferentes departamentos e institutos existentes na universidade.

Sendo assim, o presente artigo apresentada os resultados da pesquisa de doutorado realizada entre 2011-2014 junto ao Programa de Pós-graduação em Geografia Humana do DG-USP. Em nossa investigação, analisamos as mudanças ocorridas no ensino e na formação docente em geografia a partir do processo de implementação do Programa de Formação de Professores (PFP-USP) lançado por esta Universidade em 2006, compreendendo de que maneira o mesmo tem norteado as decisões institucionais e práticas que envolvem a formação do professor de geografia, bem como os desafios que traz para o DG-USP. 


\section{MATERIAIS E MÉTODO}

Para tanto, recorremos a pesquisas documentais na Instituição e em outros bancos de dados que se referem à formação de professores na USP. Além disso, aplicamos questionários e realizamos entrevistas com docentes e discentes do referido departamento e de outros institutos e faculdades da universidade que, direta ou indiretamente, tiveram algum grau de participação no processo de construção e implementação do PFP-USP, para que assim pudéssemos analisar as diferentes perspectivas e práticas que ali existem, bem como os desafios para que o programa se efetive.

O artigo encontra-se organizado da seguinte forma: iniciamos com uma breve história da formação docente na USP e suas implicações para o Departamento de Geografia. Após isso, discutimos o documento que sintetiza o PFP-USP, buscando apontar as suas principais concepções norteadoras. Na sequência, apresentamos e discutimos os dados coletados em nossa pesquisa de campo, com o intuito de compreender a percepção dos diferentes sujeitos acerca das mudanças ocorridas na formação docente em geografia com a implementação do PFP-USP.

Por se tratar de tema amplo, esperamos contribuir, com esta interpretação inicial, para suscitar, entre diferentes pesquisadores da área, problemáticas a serem melhor investigadas em pesquisas posteriores.

\section{RESULTADOS E DISCUSSÃO}

\section{A formação de professores na USP: breve resgate}

Para que possamos compreender um pouco mais acerca da formação de professores no DGUSP faz-se necessário, de forma breve, retomar o histórico da formação de professores na USP. Antunha (1974) busca compreender os ideias e processos que deram origem a esta universidade, bem como as implicações trazidas pela reforma da mesma ocorrida em 1969. Ao analisar textos de jornais e de autores da época da fundação da USP, o autor aponta que o principal objetivo desta universidade era formar as elites intelectuais de São Paulo e constituir-se enquanto um centro de altos estudos e pesquisas desinteressadas. Não havia, no momento de sua fundação, uma preocupação acerca da aplicação do conhecimento 
desenvolvido, o que demonstra que a USP não foi fundada com o intuito de formar professores.

Esta mesma ideia é reforçada por Fetizon (1984) em seu estudo sobre a formação de professores na USP. Para a autora,

Não se previa, pois, no modelo original, a formação de professores secundários no âmbito da Faculdade de Filosofia Ciências e Letras, o que estava a cargo dos Institutos de Educação; e aquela Faculdade, onde potencialmente tal formação seria feita, não era originalmente, destinada a profissionalização de nenhuma espécie. Atribuir-lhe o licenciamento para o exercício do magistério foi circunstância imprevista no modelo, que se the aplicou de fora, sem tocá-lo em sua essência básica e mesmo em sua estrutura formal (FETIZON, 1984, p.128-130).

Para os autores, esta mudança do ideal de fundação da USP ocorreu a partir de 1938 como resultado da pressão da ditadura getulista do Estado Novo e das legislações decorrentes acerca do ensino superior. Com isso, o antigo Instituto de Educação, responsável pela formação do licenciado, foi incorporado pela Faculdade de Filosofia, Ciências e Letras (FFCL), transformando-se na Seção de Pedagogia da mesma. Tal processo trouxe importantes resultados, principalmente porque inaugurou o modelo de formação de professores que ficou conhecido popularmente como $3+1$. Neste modelo, o aluno matriculava-se em um curso de bacharelado e apenas no último ano cursava três disciplinas para obter o título de licenciado.

Segundo Fetizon (1984), tal modelo contribuiu para o fortalecimento da dicotomia entre Bacharelado e Licenciatura, bem como para a construção de uma visão negativa no campo disciplinar da formação de professores, vista como de menor importância. Segundo aponta a autora, o modelo adotado a partir de 1938 inverteu a lógica daquele encontrado no período anterior (1934-1938), no qual havia uma relação de complementaridade entre o Instituto de Educação (IE) e a FFCL. No modelo anterior, o aluno que almejava o título de licenciado em alguma disciplina matriculava-se no Instituto de Educação e o cursava por três anos, tendo uma formação geral e pedagógica. Em relação à formação específica, cabia ao aluno buscá-la em diferentes fontes, inclusive na $\mathrm{FFCL}$, sendo que a partir do 30 ano do IE ele seria submetido a um prova para certificar os seus conhecimentos específicos da matéria que iria lecionar. Segundo Fetizon (1984), 
Talvez se devesse acrescentar, ainda, que esse é o único momento em que se dá prioridade à formação pedagógica na formação do professor secundário em São Paulo e se supõe a opção prévia pelo magistério como condição básica da realização dos cursos (p. 148).

A partir desta constatação, percebe-se que o estudante optava primeiro pela formação docente, sendo complementar a formação relacionada aos conhecimentos específicos da disciplina a ser ministrada. Tal modelo perdurou até 1938, quando se iniciou o modelo curricular de formação docente popularmente conhecimento como $3+1$. Tal modelo curricular foi parcialmente modificado com a reforma da USP de 1969, que resultou na fragmentação da FFCL em diversos institutos e faculdades, com a consequente criação da Faculdade de Educação (FE).

A partir daí a responsabilidade pela formação de professores nos cursos com dupla habilitação (licenciatura e bacharelado) ficou a cargo da FE. Tal processo, como veremos adiante, implicou, em muitos casos (e esta é, em parte, a realidade encontrada atualmente no DG-USP), na desresponsabilização das unidades de origem sobre a formação docentes. No modelo surgido após 1969, o aluno obtinha o título de licenciado após cumprir a carga horária do bacharelado e a carga horária destinada à licenciatura (percentualmente menor), esta última cursada integralmente na Faculdade de Educação.

A partir destas discussões é possível perceber que a formação de professores na USP nas unidades de origem dos licenciados foi constantemente marcada por conflitos e disputas acadêmicas. Seja com as mudanças ocorridas a partir da legislação federal de 1938, com a incorporação a força da formação de professores nas unidades de origem, seja com a reforma de 1969 com a criação da FE-USP e o consequente aumento da desresponsabilização da unidade de origem sobre esta formação, é possível perceber que são muitos os desafios para se pensar uma formação docente que seja capaz de romper com as dicotomias (entre bacharelado e licenciatura,ensino e pesquisa, unidades de origem e Faculdade de Educação), historicamente criadas.

Sendo assim, a análise que faremos sobre o PFP-USP e suas implicações no DG-USP levará em consideração os processos anteriormente discutidos, visto que o próprio programa surge com o intuito de colocar em discussão e problematizar tais questões. 


\section{O Programa de Formação de Professores da USP.}

O Programa de Formação de Professores da USP busca reposicionar o lugar do ensino e da formação docente nesta universidade e traz importantes implicações na dinâmica do Departamento de Geografia da mesma. Lançado em 2006 (mas implementado apenas a partir de 2008), o Programa tem como principal objetivo possibilitar uma maior articulação entre as diferentes licenciaturas existentes na USP, com o intuito de trazer à tona discussões sobre a formação de professores.

O Programa foi pensado com o intuito de adequar a formação de professores na USP as resoluções do Conselho Nacional de Educação acerca das diretrizes nacionais de formação docente $^{2}$. A partir disso, iniciou-se um importante movimento de diálogo entre os diferentes institutos e faculdades que resultou na criação da Comissão Permanente das Licenciaturas (CPL) que, posteriormente seria transformada na Comissão Interunidades das Licenciaturas (CIL). Tal comissão reunia professores de todas as licenciaturas da Universidade com o intuito de construir uma proposta coletiva de formação de professores. Como dito, a formação de professores na USP reúne uma miscelânea de cursos: em alguns casos, tal formação já estava a cargo de um instituto específico, com entrada e saída únicas, (caso da física e da matemática); em outros, ocorria a partilha da responsabilidade entre o instituto de origem e a Faculdade de Educação. O curso de geografia enquadra-se neste segundo formato, visto que existe uma única entrada e uma dupla saída, ou seja, o aluno, no interior do seu processo de desenvolvimento curricular do bacharelado opta ou não pela licenciatura.

Neste sentido, é possível compreender as dificuldades de se construir um projeto de formação de professores que leve em consideração estas diferentes perspectivas e não coíba o desenvolvimento da autonomia de cada uma destas identidades curriculares existentes. Esta afirmação se faz necessária para que possamos compreender a complexidade ${ }^{3}$ sobre a qual estamos tratando ao buscarmos analisar o processo de

2. Resolução CNE/CP 1, de 18 de fevereiro de 2002.

3. Existem atualmente 30 licenciaturas na USP, segundo que apenas uma delas (Letras) possui 15 habilitações. 
implementação do Programa de Formação de Professores da USP no Departamento de Geografia.

O programa tem como um dos seus fundamentos a crítica à atual concepção de que a formação do professor é uma mera complementação das atividades realizadas pelo bacharel. Tal concepção parte do pressuposto de que o título de licenciado em determinada área (geografia, matemática, física, etc.) é apenas um complemento do curso de bacharelado realizado anteriormente. Há, nesta concepção, uma ideia de que formar professores é meramente uma questão técnica, de formação de determinadas habilidades docentes ligadas à transmissão de conteúdos adquiridos previamente. Ausentes desta concepção estão as questões políticas, filosóficas, sociais que envolvem a formação e a atuação do professor.

Como vimos este modelo ganha força na USP a partir de 1938 e a crítica ao mesmo vai ao encontro das discussões realizadas por Tardif (2010) e que apontam para o predomínio dos saberes denominados disciplinares nos currículos de formação de professores. Tais saberes representam grande parte do espaço-tempo curricular e são visto como pré-requisitos para o desenvolvimento da ação. Foi baseado nesta concepção que se construiu o modelo de formação de professores popularmente conhecido como $3+1$ e que ainda predomina nas práticas encontradas em muitos institutos e faculdades, tanto da USP quanto de outras Universidades.

Em pesquisa realizada sobre os currículos de formação de professores no Brasil, Gatti (2008) aponta para a predominância desta dicotomia curricular, na qual se potencializa a separação entre conjuntos de disciplinas denominadas específicas e pedagógicas. Segunda a autora, "na maior parte dos ementários analisados não foi observada uma articulação entre as disciplinas de formação específicas (conteúdos da área disciplinar) e a formação pedagógica (conteúdos da docência)" (GATTI, 2008, p. 137).

Neste sentido, o PFP-USP busca construir uma proposta de articulação entre as diferentes etapas e saberes necessários a formação de professores, com o intuito de possibilitar a construção de uma identidade curricular. Para tanto, propõe uma organização curricular em quatro grandes blocos de saberes: 


\begin{tabular}{|l|l|l|}
\hline Bloco I & Formação específica & $\begin{array}{l}\text { Disciplinas e atividades diretamente relacionadas aos } \\
\text { conhecimentos da área específica. }\end{array}$ \\
\hline Bloco II & Iniciação à Licenciatura & $\begin{array}{l}\text { Disciplinas e atividades introdutórias à formação do } \\
\text { professor da Educação Básica. }\end{array}$ \\
\hline Bloco III & $\begin{array}{l}\text { Fundamentos teóricos e e } \\
\text { práticos da Educação }\end{array}$ & $\begin{array}{l}\text { Disciplinas e atividades relacionadas à formação } \\
\text { pedagógica em geral. }\end{array}$ \\
\hline Bloco IV & $\begin{array}{l}\text { Fundamentos } \\
\text { metodológicos do ensino }\end{array}$ & $\begin{array}{l}\text { Disciplinas e atividades relacionadas ao ensino das } \\
\text { áreas específicas. }\end{array}$ \\
\hline
\end{tabular}

Quadro 1: Blocos disciplinares propostos no PFP-USP

Fonte: Programa de Formação de Professores da USP, 2006.

$\mathrm{Na}$ apresentação de cada um destes blocos, discute-se a responsabilidades das unidades de origem do licenciando e da Faculdade de Educação no desenvolvimento das mesmas. Objetivando garantir, ao mesmo tempo, autonomia dos institutos e faculdades e a articulação / cooperação entre os mesmos na construção curricular, o programa busca romper com as dicotomias existentes entre os diferentes saberes necessários a formação docente.

Além desta proposta de organização curricular, o documento apresenta uma série de princípios acerca da formação de professores na USP. O primeiro deles aponta para a necessidade de que o programa seja pensado não como uma estratégia pontual, mas uma política permanente da Universidade, que exige grande esforço. O segundo propõe, como ponto de partida na formação docente, o reconhecimento da vida escolar e do exercício profissional e a importância de aproximar o futuro professor da escola. O texto é bem claro quando discorre sobre a necessidade de se pensar a preparação para o exercício profissional na escola contemporânea, uma vez que a mesma está repleta de desafios e é com esta escola real e com as práticas cotidianas que ali ocorrem, que o PFP-USP busca dialogar.

No terceiro princípio afirma-se que a formação de professores deve ter como foco a escola pública. Ao assumir isto, a Universidade busca colaborar para a transformação da educação pública que, como sabemos, a partir de pesquisas e relatos de profissionais que atuam na rede, no caso do Estado de São Paulo e em quase todo o Brasil, passa por um intenso processo de deterioração resultado de décadas de implementação de políticas neoliberais. 0 quarto princípio diz respeito à indissociabilidade entre ensino, pesquisa e extensão. Neste ponto, concebe-se a formação do professor também como um pesquisador, que seja capaz 
de pensar, de construir conhecimentos e de possibilitar aos seus alunos também esta construção.

No quinto princípio, afirma-se que a formação do professor ocorrerá durante toda a graduação. Neste momento, a tentativa é romper com a dicotomia entre disciplinas pedagógicas e disciplinas do conteúdo relacionado a matéria a ser lecionada. O que se busca é que toda a formação seja pensada a partir do objetivo de se formar o professor. Nos cursos de licenciatura, isto já deveria estar posto. Nos cursos que envolvem a dupla formação (bacharel e licenciado) esta discussão começa a ganhar força. O avanço que este princípio traz diz respeito à necessidade de se pensar a formação específica do profissional docente.

No sexto princípio há um enfretamento daquele desafio que já apontamos, qual seja, de, ao mesmo tempo, criar uma estrutura de formação articulada e permitir as especificidades de cada um dos cursos. O sétimo princípio coloca o diálogo entre universidade e escola. Além de aprofundar o debate acerca do estágio supervisionado, tal princípio amplia a concepção de que a educação pública não se restringe apenas as escolas regulares e formais, mas a diferentes outros espaços (sindicatos, igrejas, secretarias). Ao mesmo tempo, ao dizer que a proposta pedagógica da escola deve ser o eixo norteador do estágio supervisionado, coloca a necessidade de que o futuro professor não seja um missionário na escola, mas um pesquisador, um colaborador no sentido em que vai reconhecer os lugares, reconhecer a escola e seus diferentes sujeitos enquanto lugar de produção do conhecimento.

Portanto, nestes princípios é possível perceber uma tentativa de articulação entre os diferentes conhecimentos ligados a formação de professores: a criação de identidades curriculares específicas desta formação, a relação próxima entre escola e universidade, a ênfase dada à educação pública. Todos estes elementos são essenciais, em nossa perspectiva, na formação de professores. Contudo, isso não significa dizer que na prática tais processos se realizem. Como o próprio documento apresenta, existe uma série de desafios a serem enfrentados:quais são os enfrentamentos? Quais são as dificuldades que o PFP-USP no interior da Universidade? Como isso se realiza, no DG-USP? Estes são os desafios que discutiremos a seguir.

\section{Dos discursos às práticas}


Como dissemos, o programa de formação de professores da USP entrou em vigor no ano de 2006, trazendo importantes mudanças na dinâmica curricular do DG-USP. Significou a entrada na grade curricular de duas novas disciplinas (Ensino de Geografia para o Ensino Básico e Estágio supervisionado de Ensino de Geografia e Material Didático). A primeira delas visa dar mais possibilidades de escolha aos alunos já que podem optar entre essa disciplina oferecida pelo Departamento e a disciplina de Introdução de Estudos da Educação (com enfoque histórico, sociológico ou filosófico), oferecida na Faculdade de Educação. Já a segunda deve ser feita obrigatoriamente pelos discentes do curso de geografia, preferencialmente a partir do quinto semestre do curso de bacharelado. A disciplina de estágio supervisionado conta com 100 horas dedicadas a prática do estágio, concebida de forma ampla e multidisciplinar, envolvendo diferentes atividades relacionadas ao ensino de geografia e que não se restringem a educação formal. Além disso, as atividades práticas como componente curricular (PCCs) aparecem como fundamentais na formação docente.As 400 horas das PCCs aparecem distribuídas da seguinte maneira entre as disciplinas que compõem a grade curricular do curso de geografia: 12 horas para todas as obrigatória de 60 horas, 6 horas para as de 30 horas.Além disso, os alunos da graduação em geografia precisam cumprir 200 horas de Atividades Acadêmico-Científico-Culturais (AACCs), que vão desde participação em seminários, grupos de pesquisa, monitorias até a atuação no movimento estudantil organizado (Centro Acadêmico, Diretório Central dos Estudantes).

No entanto, para que estas mudanças curriculares possam se efetivar realmente alguns processos tornam-se essenciais. Entre eles, destacamos a necessidade de maior participação dos diferentes sujeitos do DG-USP na implementação da PFP-USP. Tal constatação se deu a partir da aplicação de questionários ${ }^{4}$ e de entrevistas realizadas com professores e alunos do curso de Geografia da USP pelas quais é possível perceber que ainda falta uma participação mais efetiva nas discussões acerca do próprio programa.

Acho que é uma questão ainda pouco discutida e que a não discussão do currículo do DG como um todo, somente a introdução das necessidades do programa de formação de professores da USP, é um erro e depende somente da posição e boa vontade do docente de discutir ou não a questão do ensino mais diretamente. Sabemos que por meio de suas práticas, o

4. Foram aplicados questionários a 15 professores e a 160 alunos do DG-USP. 
docente já cumpriria o desejado no programa de formação de professores da USP. Mas ainda considero que é uma prática a ser construída e que deve ser precedida de maior discussão (Docente DG-USP, resposta ao questionário, maio de 2012).

É possível perceber pela fala anterior a necessidade da ampliação do de diálogo entre os docentes e discentes do curso acerca das implicações trazidas pelo novo PFP-USP. Tal ampliação é fundamental para que os princípios do mesmo sejam compreendidos, analisados e criticados a ponto de produzirem mudanças nas práticas formativas. De outra forma, corre-se o risco de que as mudanças sejam apenas burocracias, previstas nas ementas das disciplinas, mas distantes das práticas necessárias à formação de professores.

Um indício desta adequação burocrática pode ser verificado também na análise nas ementas e programas dos cursos. Em um total de 24 ementas e programas analisados (os programas se referem aos anos de 2012 e 2013), apenas três fazem referência direta a educação básica e o ensino de geografia.Outro ponto a ser destacado é que não há, nem nas ementas, nem nos programas, detalhamentos acerca de como as PCCs serão desenvolvidas, bem como a relação com os outros objetivos e conteúdos da disciplina.

Outro ponto observado é que ainda se mantém certa hierarquia entre os diferentes conhecimentos e formações existentes no DG-USP que trazem implicações no processo de implementação do PFP-USP, como pode ser visto na resposta obtida através do questionário aplicado.

\begin{abstract}
Sinto que há no departamento de geografia muito mais valorização da formação dos alunos na área de pesquisa e no exercício profissional de geógrafo do que na formação de professores. Os próprios docentes negligenciam sua postura de educador dentro da sala de aula e acabam dando exemplos ruins para os alunos que serão futuros professores. Eles esquecem que, antes de tudo, a postura do docente em sala de aula é um exemplo para estes futuros professores (Docente DG-USP, resposta ao questionário, março de 2013).
\end{abstract}

$\mathrm{Na}$ fala, é possível perceber que ainda predomina a concepção de que a formação do bacharelado é pré-requisito para a formação do professor. Nesta perspectiva, a pesquisa enquanto elemento fundamental da construção do conhecimento está, essencialmente, vinculada as atividades desenvolvidas pelo bacharel, aparecendo apenas em alguns momentos na formação do licenciado. Em nossa perspectiva, esta concepção pouco altera a 
compreensão sobre a formação docente presente na modalidade $3+1$ que o PFP-USP quer superar.

Portanto, tal debate pressupõe reconhecer a articulação necessária entre as diferentes disciplinas que compõem o currículo e o reconhecimento de que na formação de professores a mobilização dos conhecimentos se dá a partir de outras problemáticas. Como apontava Azanha (1991).

Este debate, porém, dificilmente será feito sem dificuldades, porque qualquer proposta de alteração da formação do magistério no âmbito da USP colidirá com situações e interesses, institucionais e pessoais, já consolidados. Uma coisa também é clara: sem um elevado espírito acadêmico e público, nenhum progresso substancial será obtido com relação ao exame do assunto e sem esse progresso a USP poderá ver reduzida sua presença, tradicionalmente de liderança, na rede de escolas públicas do Estado de São Paulo (1991, p. 37).

Nas entrevistas realizadas, tais conflitos apontados pelo autor apareceram. Um dos primeiros diz respeito à certa desconfiança mútua entre os professores da Faculdade de Educação (FE) e os docentes dos outros cursos de Licenciatura da USP. Tal desconfiança, segundo os entrevistados, era mais acirrada entre a FE e a Faculdade de Filosofia, Letras e Ciências Humanas (FFLCH), na qual está inserido o DG-USP Entre os motivos apontados para tal conflito está o processo que envolveu a reforma Universitária de 1968 e a reforma da USP de 1969 e que modificou a estrutura acadêmica e política da USP. Segundo um dos entrevistados 5

A impressão que eu tenho é que a FFLCH tinha uma imagem da Faculdade de Educação que tem a ver com os anos 70, tem a ver com o fato de que uma dos chefes, uma pessoa importante aqui, que foi diretor da faculdade, o Roque Spencer, participou da reforma Universitária de 1968, que não é a mesma coisa do que foram os decretos, os atos institucionais de intervenção na faculdade (a reforma sai em julho, os atos saem no final de 68), mas a Universidade B costuma por tudo no mesmo saco. Mas ficou esta imagem da Faculdade de Educação e uma imagem que nada tem a ver com o corpo docente que tem aqui hoje (Docente FE-USP, entrevista ao pesquisador, fevereiro de 2011).

5. Docente da FE-USP. Presidiu a comissão que elaborou o Programa de Formação de Professores da USP. 
A esta desconfiança soma-se outra acerca das mudanças curriculares que poderiam surgir a partir da adoção do PFP-USP. Segundo outro entrevistado ${ }^{6}$,

O que aconteceu é que, de repente, por determinação da nova lei das diretrizes do MEC estabeleceu-se uma carga enorme para as chamadas práticas de ensino ou práticas educacionais... E quando isso apareceu, você imagina o que foi no departamento. Onde nós vamos enfiar? Vai ter que tirar aulas de geografia? Vai ter que dar aulas de bacharel ao lado?... Até que a Faculdade de Filosofia começou a entender que não haveria sacrifício para a carga do bacharelado. (Docente DG-USP, entrevista ao pesquisador, abril de 2011).

É possível perceber que, em certa medida, o desconforto causado pelo programa, relatado no trecho acima, está relacionado ao fato de que, na percepção de alguns docentes da FFLCH, o mesmo poderia significar uma diminuição da carga horária das disciplinas do Bacharelado. Além disso, o que está em jogo é a responsabilidade de cada uma destas unidades de ensino acerca da formação de professores, como aponta outra entrevistada:

A dificuldade que nós tivemos na CIL foi exatamente este embate com a Faculdade de Educação. Foi desde o começo o que vai para aqui, o que vai para lá. A faculdade de Filosofia resistiu muito em fazer alguma coisa, pois a ideia era que nos já formávamos professores que iam fazer na Faculdade de Educação as disciplinas pedagógicas e pronto. Não era isso que a gente queria. Assumir um compromisso era superar também os problemas. E o três mais um era um problema enorme. Os alunos questionavam muito em todos os fóruns de graduação esta coisa que ficava descolada uma coisa da outra: uma coisa aqui, outra coisa lá, e outra coisa o que eles iam encontrar na escola. Então a ideia era ao mesmo tempo responder as exigências da legislação, mas também mudar a concepção de ensino (Docente representante do Departamento de História na CIL, entrevista ao pesquisador, agosto de 2012).

Portanto, é possível perceber que os embates curriculares marcaram o início do processo de implementação do PFP-USP. Não se tratava apenas de adotar medidas para que a USP pudesse se adequar a legislação federal. Era necessário também expor os problemas do modelo de formação de professores que predominava até aquele momento. E por isso a ocorrência dos embates entre as unidades, uma vez que há, principalmente na relação entre FE e FFLCH, uma dicotomia de responsabilidades, a qual o PFP-USP propunha discutir.

6. Professor aposentado do Departamento de Geografia da USP e que participou das discussões para a construção do PFP-USP. 
Além disso, existem disputas curriculares no próprio DG-USP, como aparece na fala de uma das professoras entrevistadas.

E esta é uma outra particularidade da geografia que se refletiu fortemente na discussão do currículo, que era uma briga entre áreas. Alguns professores de geografia humana diziam: a geografia humana é mais ampla e complexa de que a geografia física, então ela tem que ocupar uma maior parte do currículo. E os professores da geografia física diziam: não, a geografia física tradicionalmente tem um lugar de destaque na geografia da USP e, além disso, muitos de nossos alunos vão se colocar no mercado de trabalho por causa de disciplinas da geografia física. Então ficou este embate, esta dificuldade de achar um meio termo e a discussão caiu em um marasmo (Docente do DG-USP, entrevista ao pesquisador, maio de 2012).

Em meio aos embates em busca de um melhor posicionamento na hierarquia do campo científico, os representantes das diferentes áreas e conhecimentos da geografia ainda não conseguiram construir uma proposta coletiva de formação, tanto do bacharel quanto do licenciado. Além disso, há que se considerar que nas últimas décadas vêm ocorrendo um acirramento das disputas entre as diferentes disciplinas da geografia, decorrentes também da especialização impulsionada pelo Produtivismo (CRUZ, 2012) e que produz uma situação na qual o trabalho coletivo de elaboração curricular é cada vez mais substituído pela busca dos próprios interessantes.

Outro desafio no processo de implementação do PFP-USP no DG está em fazer com que tanto os estágios quantos as PCCs se tornem efetivos elementos articuladores dos currículos de formação de professores. Este desafio já era apontado no texto de AZANHA

Nas unidades que organizarem o seu próprio curso de licenciatura talvez seja conveniente que a Prática de Ensino possa ser tratada sob múltiplas formas, como estágios, instrumentação dos licenciados, o que não exclui o tratamento disciplinar convenientemente esclarecido. Talvez não convenha que a orientação, o acompanhamento e a avaliação dessa preparação sejam confiados a um único docente, mas a uma comissão geral e renovável, em todos os anos letivos, pelo menos parcialmente. $\mathrm{O}$ assunto, nestes termos, seria da responsabilidade de toda a escola e garantiria uma colaboração interdisciplinar (1991, p. 40).

Para o autor, é evidente a necessidade de se repensar o papel e a função dos estágios e das PCCs no processo de articulação dos currículos de formação de professores. Sem isto, correse o risco de se manter a personificação de tais atividades. Além disso, é importante ressaltar que esta discussão pode fomentar um debate mais amplo sobre a organização curricular e incentivar o trabalho coletivo entre os professores da Universidade. 
Em nossa pesquisa, vimos que ainda existe certo desconhecimento dos discentes do DG-USP acerca das PCCs e sua a função curricular. Tal desconhecimento pode ser verificado a partir dos resultados a seguir:

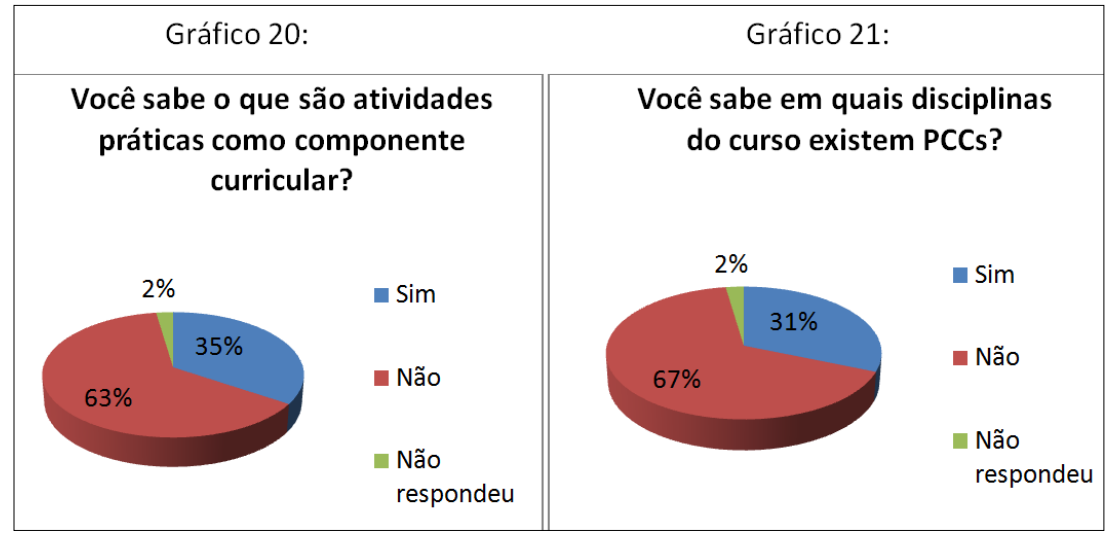

Figura 1: Percepção discentes sobre as Práticas como Componente Curricular no DG-USP. Fonte: Eduardo Donizeti Girotto (2012).

É possível perceber que ainda é grande o número de discentes que não sabem quais o significados das PCCs e quais disciplinas têm carga horária destinada para esta atividade. Tal informação vai ao encontro dos dados apresentados anteriormente em relação a forma como as ementas das disciplinas estão organizadas, o que pode revelar um tratamentoburocrático das PCCs no currículo. Esta necessidade de alargamento de compreensão do que se constituem as mesmas apresenta-se como imperiosa, uma vez que a mesma não está clara nem para os docentes (conforme aponta a análise dos programas e ementas), nem para os discentes, o que pode ser percebido no gráfico a seguir:

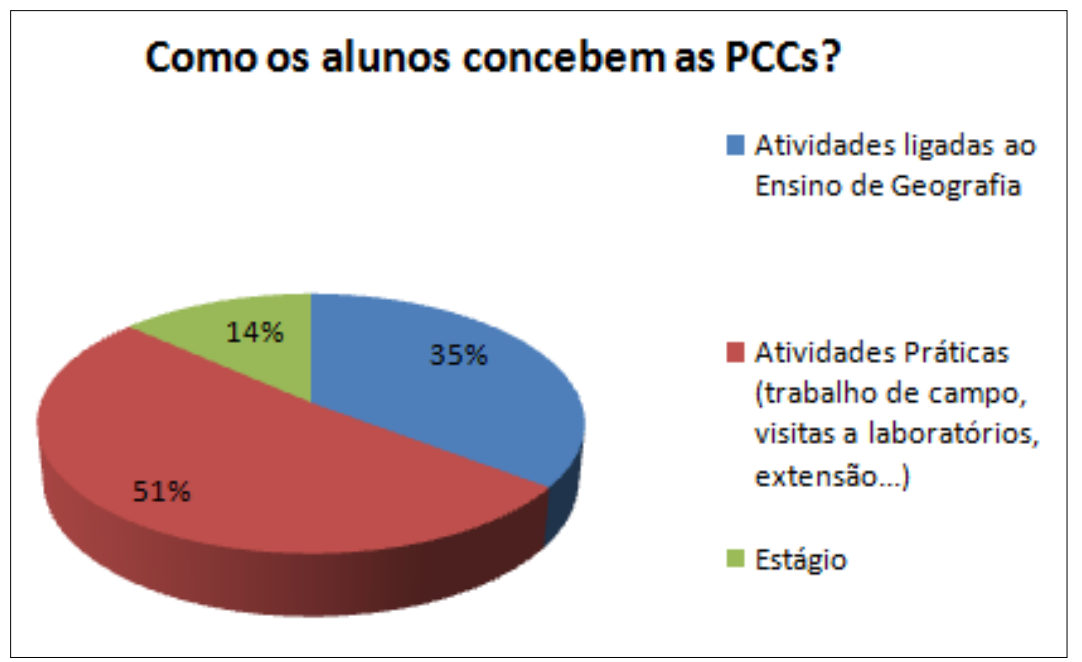

Figura 2: Concepção discente sobre as Práticas como Componente Curricular no DG-USP. Fonte: Eduardo Donizeti Girotto (2012). 
É possível perceber que existe uma confusão entre PCCs e outras modalidades de atividades práticas, não necessariamente vinculadas à formação docente, como trabalhos de campo, visitas a laboratórios, atividades de extensão, entre outras. Além disso, é considerável o número de alunos que as concebem como atividade de estágio.Porém, no gráfico a seguir, é possível inferir que o PFP-USP tem contribuído para a ampliação da busca por outras formas e estratégias de desenvolvimento das PCCs no DG-USP, que coloquem em diálogo o conhecimento da geografia acadêmica com aquele fundamental para o ensino e aprendizagem de geografia na educação básica.

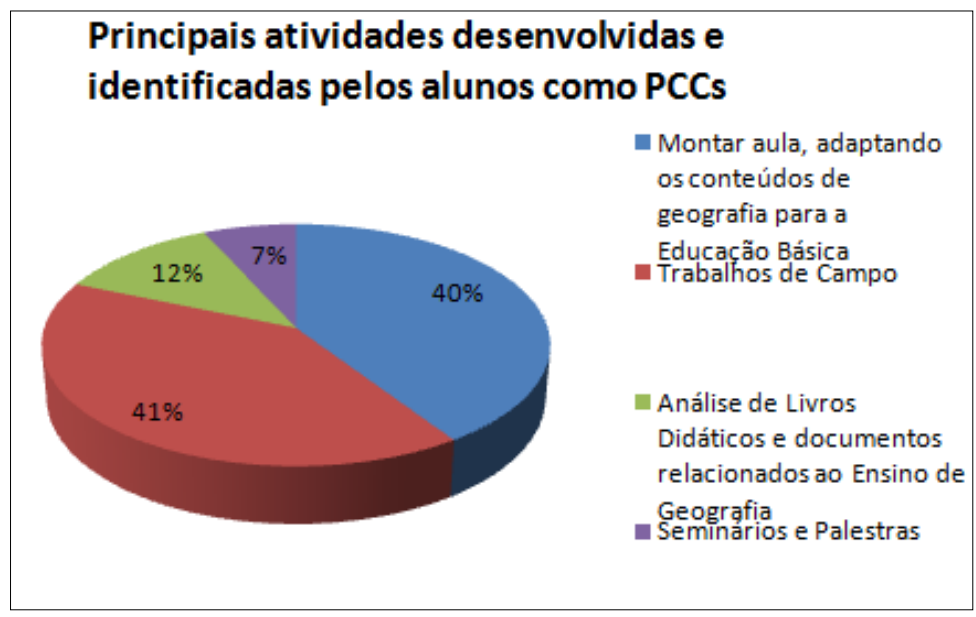

Figura 3: principais Práticas como Componente Curricular desenvolvidas no DG-USP segundo os discentes. Fonte: Eduardo Donizeti Girotto (2012).

Em nossa pesquisa de campo, acompanhamos algumas atividades de problematização da prática docente, que evolvem a relação entre os currículos da educação básica e aqueles conhecimentos historicamente desenvolvidos pela ciência geográfica. Um dos exemplos pode ser encontrado na PCCs desenvolvidas pelos alunos durante a disciplina Introdução a Cartografia (1으 semestre), ministrada pelo professor Alfredo Queiroz. Nesta atividade, os alunos foram instigados a construir estratégias didáticas para trabalhar com noções de cartografia com alunos da educação básica. Os resultados desta atividade podem ser visto nas imagens a seguir: 

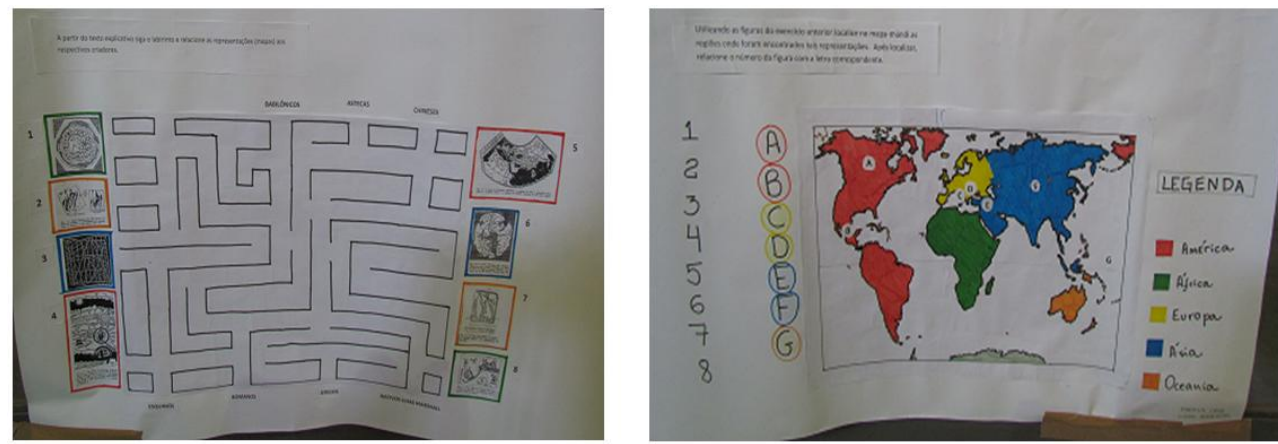

Figura 4: PCC feita pelos discentes da USP para trabalhar com Cartografia.

Fonte: Eduardo Donizeti Girotto (2012).

Tais atividades podem parecer de pouco importância, mas gostaríamos de reforçar o significado das mesmas a partir da nossa experiência como aluno do curso de geografia do DG-USP (entre 2001 e 2005). Durante os cincos de graduação no Departamento, em apenas uma disciplina (Regionalização do Espaço Brasileiro) houve uma tentativa de aproximação feita pelo professor entre o conhecimento acadêmico e o conhecimento escolar. De resto, tais atividades ficaram restritas as práticas de estágio supervisionado, que ocorreram na Faculdade de Educação. Portanto, encontrar experiências de diálogo entre a Educação Básica e o conhecimento de geografia construído no DG-USP é uma prova que, apesar de todas as dificuldades discutidas anteriormente, O PFP-USP já tem produzido algumas importantes implicações na forma de organizar e executar o currículo, com algum ganho no que diz respeito à valorização da formação docente.

Outro exemplo ocorreu durante atividade acompanhada em 2011, na disciplina de Estágio e Produção de Material Didático em Geografia no DG-USP. A atividade consistia em, a partir de diferentes linguagens (vídeo, poesia, música, cartografia) construir aulas para a Educação Básica sobre temas referentes à Geomorfologia. A atividade colocou em diálogo dois professores do curso, a partir das disciplinas de Geomorfologia I e Estágio Supervisionado de Ensino de Geografia e Material Didático.

No decorrer da atividade, foi interessante perceber o trabalho dos alunos em reelaborarem o conhecimento produzido no âmbito da Universidade sobre temas da geomorfologia para a educação básica. A proposta de trabalhar com diferentes linguagens, a partir das contribuições de Bakhtin, contribuíram para o desenvolvimento da atividade. 
$\mathrm{Na}$ avaliação feita pelos alunos, foi apontada a dificuldade de usar as diferentes linguagens de maneira didática, reelaborando o conhecimento acadêmico na direção do conhecimento escolar. Tal avaliação traz à tona a maneira com o desenvolvimento das PCCs coloca o currículo em movimento e faz dialogar diferentes dimensões do conhecimento, essenciais para a formação de professores. Esta problemática pode ser vista na fala de outro aluno que também apontou para o desafio e as dificuldades de articular conhecimento acadêmico e conhecimento escolar. Para tal aluno, o desenvolvimento da PCC propiciou a tarefa de selecionar aquilo que é relevante e considerar a realidade dos alunos na construção de uma aula. Além disso, para este aluno, a atividade obrigou os graduandos a pensarem acerca da prática de ensino, uma vez que até aquele momento ( $2^{\circ}$ ano do curso de geografia) era a primeira vez que eles discutiam assuntos específicos relacionados à formação docente.

A observação deste aluno levou outro a apontar para a necessidade de que as PCCs não deveriam ficar isoladas, restritas a uma disciplina, mas incluir outros temas e conhecimentos no debate, permitindo assim uma transversalidade da temática educacional no curso. Tal proposta, por sua vez, traz novamente o desafio de se pensar o currículo como um elemento integrador e articulado e vai na direção contrária a forma como o conhecimento acadêmico e o trabalho docente do professor universitário está organizado no momento atual, pautado na ação individual.

Esta percepção acerca da necessidade de se ampliar o espaço da formação docente no currículo do DG-USP busca problematizar a atual situação revelada pelo gráfico a seguir:

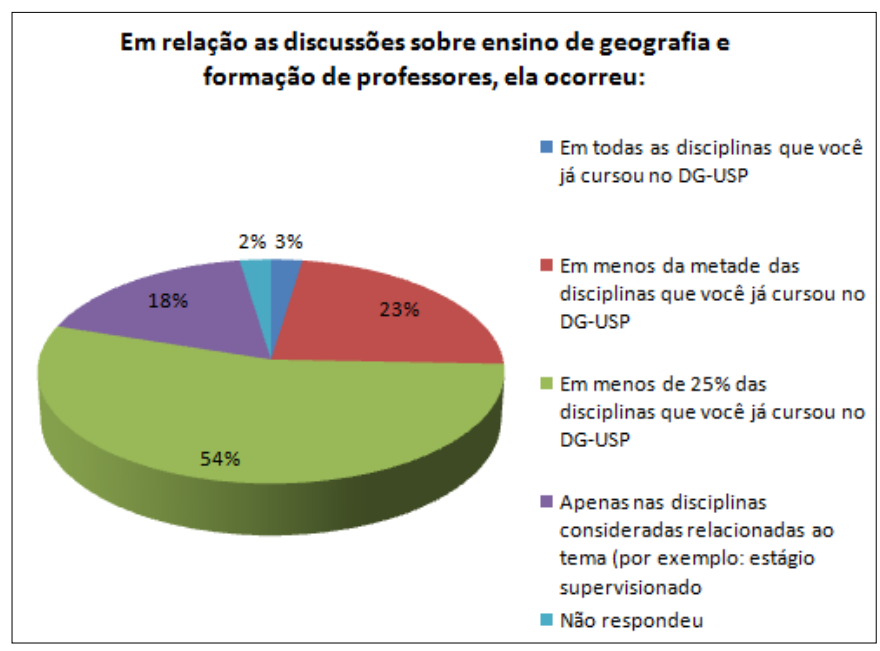

Figura 4: Percepção discente acerca das discussões sobre ensino e formação em docente em Geografia no DGUSP. 
Fonte: Eduardo Donizeti Girotto (2012).

Apesar de estar em todas as disciplinas obrigatórias, as discussões sobre ensino de geografia e formação de professores, instigadas pelas PCCs ainda se encontram restritas na organização curricular. Ainda são poucos os professores, na percepção dos discentes, que tem se colocado o desafio de discutir tais temáticas, articulando-os com os conteúdos da disciplina. Em muitas das respostas dos discentes, ainda é a clara a personificação de tais temáticas no currículo do DG-USP. Alguns professores e algumas disciplinas são vistas como as únicas responsáveis por desenvolver estas discussões, o que contradiz aquilo que está posto no PFP-USP.

Esta restrição das discussões acerca do ensino de geografia e da formação de professores pode também ser explicada por outras questões. Segundo um dos discentes que participou das atividades acompanhadas, uma das dificuldades de desenvolver as PCCs articulando inúmeras disciplinas está, também, na resistência dos professores das disciplinas específicas que argumentam que as PCCs irão diminuir as horas dedicadas a construção do conhecimento considerado estritamente científico. Tal percepção vai ao encontro das discussões já apresentadas anteriormente sobre a relação entre bacharelado e licenciatura no DG-USP.

Neste sentido, apesar de pequenas, as mudanças no currículo do DG-USP já começam a ser percebidas, como pode ser verificado na fala de um discente ao comparar as diferenças existentes no currículo antes e após o processo de implementação do PFP-USP.

A licenciatura que eu fiz aqui é um curso que não se pôs na medida necessária uma reflexão do ensino. Uma coisa que angustia é saber que eu não fui indagado e o curso não se colocou a pensar como é que o aluno aprende. Isso não foi posto, esta pergunta não foi feita na minha graduação. Você chega na sala de aula e você não tem as mediações necessárias para este processo. Digamos que até em termos do que seria a geografia, do que propõe, do que se coloca a minha formação até deu conta, mas as mediações para isso elas faltaram em muito na minha formação (Aluno do DG-USP, entrevista ao pesquisador, dezembro de 2012).

Para o entrevistado, apesar das dificuldades, a implementação do PFP-USP significou um avanço qualitativo na formação do licenciando, principalmente porque passou a criar uma relação mais direta entre ensino e pesquisa, mediada pelo estágio supervisionado. Para o 
entrevistado, houve uma mudança na concepção e do significado do estágio após a implementação do Programa.

As disciplinas na pedagogia, como ela são mais massificadas, recebe todo mundo, você faz o estágio como quiser, tem uma abertura gigante para a execução do estágio, para pensar o estágio como você quiser, eu sinto que isto desqualifica, não dá um direcionamento adequado para a formação de professores. Ao adotar uma perspectiva de estágio que considera a pesquisa, isso qualifica a discussão. Você coloca uma pauta e através de um debate, de uma discussão você consegue avançar no debate, suprir algumas angustias profissionais, pessoais e que envolvem a prática do professor ou do futuro professor. (Aluno do DG-USP, entrevista ao pesquisador, dezembro de 2012).

No Departamento de Geografia da USP, após o processo de implantação do programa de formação de professores, ocorreram importantes mudanças na relação entre ensino e pesquisa na formação docente em geografia. Tal relação fica mais explícita pela forma com o estágio supervisionado vem sendo pensado. Não se trata apenas de uma ação burocrática. 0 discente entra em contato com a escola após desenvolver um projeto de pesquisa. Sua relação, portanto, é norteado por discussões acerca de temas, problemáticas e metodologias que envolvem a prática docente e o desenvolvimento da geografia escolar. Dessa forma, há um reconhecimento de que a pesquisa constitui-se em um elemento fundamental na formação do professor para a escola contemporânea, resgatando muitos dos processos verificados em outros momentos do Departamento de Geografia da USP.

As mudanças com a criação da disciplina de estágio supervisionado no DG-USP trazem também outro importante desafio, qual seja, a necessidade de se construir um planejamento coletivo que ponha em diálogo os professores da FE e aqueles do DG que atuam nas disciplinas de estágio. Com a partilha da responsabilidade acerca da prática de estágio supervisionado, (400 horas sob coordenação da FE e 100 horas do DG), é fundamental que sejam discutidos os pressupostos que nortearão esta prática, que não pode ser concebida como algo fragmentado. Ao contrário, é preciso possibilitar ao licenciado a compreensão da continuidade de seu processo formativo, entendendo a articulação necessária entre a FE e o DG. No entanto, tal diálogo ainda está distante de ser realizado.

Infelizmente não é feito este projeto em conjunto. Meu sonho seria que a gente conversasse mais e que a gente tivesse uma parceira maior. Mas não acontece isso. Então elas são independentes. Então nós temos 400 horas e a gente se vira aqui e eles têm 100 horas lá e eles fazem as atividades lá. 
Muitas vezes eu acho que quem perde é o aluno. Por quê? Porque se a gente conversasse, o aluno poderia fazer um estágio comigo de metodologia e um estágio lá e a gente minimamente conversaria sobre o que ele vai olhar, o que ele vai observar, como é que as coisas poderiam ser articuladas. $\mathrm{O}$ que ele pode aproveitar de um estágio que ele fez lá conosco e avançar naquele estágio que ele fez. Então eu acho que está é uma lógica que eu acho que a gente não conseguiu implementar na USP (Docente da FE-USP, entrevista ao pesquisador, agosto de 2012)

É preciso, portanto, avançar na institucionalização deste debate, reconhecendo-o como fundamental na construção de um projeto de formação de professores efetivamente compartilhado. Não é possível fazê-los apenas dependendo das ações pessoais, por mais que consideramos essencial tal compromisso. No entanto, cabe a Pró-reitoria de Graduação construir políticas institucionais que fomentam o diálogo entre os diferentes sujeitos responsáveis pela formação docente. A partir das análises feitas nesta pesquisa, temos que a institucionalização destas práticas deve se dar em dois níveis: de um lado, ações que fomentem o diálogo interunidades (a Comissão Interunidades das Licenciaturas e as Jornadas das Licenciaturas são exemplos disso, mas é preciso construir ações mais cotidianas, que envolvam o diálogo entre os docentes de estágio, por exemplo); de outro, ações na própria unidade, como debates e avaliações constantes acerca da implementação do programa nos departamentos específicos). Tais ações, em nossa perspectiva, são essenciais para o PFP-USP ganhe corpo e prática nas ações dos docentes e discentes e não seja mais apenas "uma aceitação mais silenciosa e não envolvida" (Profa. representante da CIL no Departamento de História, entrevista realizada em agosto de 2011).

\section{CONSIDERAÇÕES FINAIS}

Portanto, é possível perceber que existem, apesar das disputas envolvendo questões acadêmicas e institucionais, avanços importantes no processo de implementação do PFPUSP. Para que tais avanços possam contar com participação de mais professores na construção de um projeto de formação de professores para o DG-USP, sistematizaremos a seguir os desafios a serem ainda enfrentados, para que aquilo que está posto no discurso não se torne letra morta.

Em primeiro lugar, é preciso enfrentar seriamente o desafio de articular as disciplinas que compõem o currículo de geografia, considerando as especificidades das formações do 
bacharel e do licenciado. Tal desafio pode ser acentuado se não se construir uma ampla discussão permanente de acompanhamento e avaliação acerca das implicações decorrentes da implementação do Programa. Corre-se o risco de que as duas novas disciplinas criadas para tratar das questões relacionadas ao ensino e a formação de professores em geografia passem a ser identificadas como as únicas responsáveis pela formação docente, reproduzindo assim a dicotomia já discutida no decorrer desta tese entre conhecimentos ditos pedagógicos e conhecimentos específicos. A superação deste processo, como vimos, passa necessariamente por um trabalho coletivo de discussão acerca da identidade curricular dos cursos e dos elementos ligados a construção desta identidade, como os estágios e as PCCs. Como aponta uma dos professores que responderam ao questionário:

Penso que seja possível notar já alguns resultados, entre eles o aumento do número de monografias que tratam do ensino de geografia apresentadas no DG. Mas é preciso mudar a compreensão dos professores de um modo geral, que devem assumir ser esta uma responsabilidade de todos e não apenas dos docentes diretamente envolvidos nas disciplinas que fazem parte do programa (Docente do DG-USP, resposta ao questionário, março de 2012)

Por outro lado, faz-se necessário uma retomada do compromisso com a escola pública que marcou a dinâmica deste Departamento em momentos anteriores. O processo de desvalorização social da profissão docente precisa ser alvo de investigação e questionamento por parte dos docentes e discentes do Departamento e não ser encarado como algo irreversível. Experiências como a da Semana de Geografia, da Jornada de Geoensino, entre outros, nos quais ocorre um intenso diálogo entre experiências desenvolvidas em escolas públicas paulistas e as práticas formativas do Departamento de Geografia da USP são importantes instrumentos de problematização desta realidade. Mas é importante ir além e reconhecer o potencial da escola pública enquanto lugar de pesquisa e de produção do conhecimento. Para tanto, faz-se necessária a construção de outro olhar sobre a escola pública contemporânea, que leva em consideração a sua complexidade e potencialidade investigativa.

Da mesma maneira, a implementação do Programa enfrenta dificuldades relacionadas à falta dos investimentos previstos e necessários como essenciais para sua realização. Segundo o documento do Programa, 
A viabilização deste Programa pressupõe a contratação de docentes, educadores e técnicos, assim como o estabelecimento de uma infraestrutura capaz de fornecer o apoio necessário para o desenvolvimento das ações aqui programadas (2004, p. 37).

No entanto, no caso do Departamento de Geografia da USP ocorreu, até o presente momento, apenas a contratação de um docente para atuar na área de ensino e formação de professores. Mais grave ainda é o que tem acontecido com a função de educador: a contratação de um educador concursado foi substituída, até o momento, pela contração de um monitor, bolsista de pós-graduação, com experiência na educação básica e que cumpre carga de trabalho de 20 horas semanais. O papel do educador no Departamento de Geografia da USP é mediar a relação entre os graduandos e a escola pública, orientando na construção dos projetos de investigação e pesquisa construído durante o estágio supervisionado.

Em entrevista concedida, o então monitor do Departamento de Geografia da USP apontou as dificuldades da função que desempenha.

E isso compromete porque eu sinto que o educador aqui tem que estar em constante reformulação, em constante estudo, eu preciso ler teses sobre educação, eu preciso ler sobre a proposta, e não tenho como ter esta imersão por conta de minha pesquisa de mestrado, por conta de ter um trabalho em escola, da mesma forma que compromete ter uma jornada tripla como professor (Monitor do DG-USP, entrevista ao pesquisador, dezembro de 2011).

É interessante notar que durante esta entrevista, o monitor confessou-nos que não conseguiria continuar no cargo devido à sobrecarga de trabalho e as dificuldades de finalização de sua pesquisa de mestrado. Tal fato nos revela os limites que a função do monitor bolsista traz para a implementação do Programa de Formação de Professores da USP e que este é, portanto, um dos principais desafios infraestruturais a serem enfrentados. Além disso, um outro desafio consiste em construir um processo permanente de avaliação do Programa, que institucionalize as ações nas diferentes unidades e permita compreender efetivamente os desafios a serem enfrentados e superados. Tal ação precisa ser assumida efetivamente pela universidade, dotando a CIL das condições necessárias para a realização deste processo. Não se trata apenas de verificar as condições infraestruturais dos processos, mas de criar mecanismos que sejam capazes de avaliar as dificuldades relacionadas à compreensão e prática do programa. O que significa dizer, cabe a universidade verificar se 
os efeitos do Programa no que diz respeito a qualidade da formação do docente, bem como os efeitos desta formação na educação pública.

Frequentemente a gente faz questionário para ver. Tem unidade que ainda nem tem o docente específico. Então é em grau variado que o programa entrou nas unidades. Tem unidade que professor foi deslocado para professor fazer a função e não teve a contratação ainda. Então a avaliação ainda muito em termos de estrutura para a coisa. Quando os questionários veem é sobre se existem cursos voltados para a licenciatura, quantos alunos frequentam, se está dando certo ou se tem professor, se tem o monitor bolsista ou educador. Mas em termos de conteúdo para ver se formou melhor o professor ou não isso ainda não foi feito. Isso ainda é uma coisa que eu não sei por qual caminho a gente fará. Cada unidade vai sentindo (Docente representante do Departamento de História na CIL, entrevista ao pesquisador, agosto de 2012).

Vale ressaltar que tal mudança requer uma ação política da Universidade em assumir efetivamente a formação de professores como uma de suas principais responsabilidade. Temos que o primeiro passo desta ação política foi dado com a construção do PFP-USP. O segundo, ainda não realizado, está em fazer com que o programa se efetive e seja capaz de mudar os rumos da formação de professores na Universidade de São Paulo.

Por fim, como provocação, cabem as palavras de AZANHA:

Ou a USP, globalmente, assume a sua responsabilidade social de formar adequadamente licenciados para liderança do magistério público ou reconhece, explicitamente, que falhou historicamente com relação a essa tarefa de alta importância social, mas talvez de escasso interesse acadêmico, e abre mão dessa atribuição ensejando a busca de soluções extrauniversitárias, inteiramente possíveis. $O$ que não mais é possível é a permanência, por tão longo tempo, de uma situação crítica não enfrentada. (1991, p. 38)

\section{BIBLIOGRAFIA}

ANTUNHA, H. C. G. Universidade de São Paulo: fundação e reforma. São Paulo: CRPE, 1974.

AZANHA, J. M. P. "Uma reflexão sobre a formação do professor da escola básica" IN: Educação e Pesquisa, São Paulo, volume 30, número 2, maio-agosto de 2004.

. "Uma proposta para Licenciatura na USP". Conferência na USP. 1991.

BRASIL. MEC. Resolução CNE/CP 1, de 18 de fevereiro de 2002. Institui Diretrizes Curriculares Nacionais para a Formação de Professores da Educação Básica, em nível superior, curso de licenciatura, graduação plena. Brasília: MEC, 2002.

CRUZ, Rua de C. A. da. "Universidade Classe Mundial: paradoxo de um pensamento ao mesmo tempo neoliberal e neocolonialista". 2012. 
. "Se a CAPES somos nós, quem somos nós? A pós-graduação brasileira em busca de uma identidade". 2012.

FÉTIZON, B. A. de M. Educar professores? Um questionamento dos cursos de licenciatura da Universidade de São Paulo. São Paulo: FEUSP, 1984.

GATTI, B. A. et al. "Formação de professores para o Ensino Fundamental: instituições formadoras e seus currículos" IN Estudos e Pesquisas Educacionais. № 1, maio de 2010. Fundação Victor Civita, São Paulo.

TARDIF, M. Saberes Docentes e formação profissional. 11a edição. São Paulo: Vozes, 2010.

$$
\text { Artigo submetido em 22/10/2014 }
$$

Artigo aceito em 26/01/2015 